\section{BRAZIULIAN JOURNAL}

OF MEDICAL AND BIOLOGICAL RESFARCH

www.bjournal.com.br
ISSN 0100-879X

Volume 43 (5) 381-496 May 2011

BIOMEDICAL SCIENCES

AND

CLINICAL INVESTIGATION

Braz J Med Biol Res, May 2011, Volume 44(5) 453-459

doi: 10.1590/S0100-879X2011007500024

Anthropometric midarm measurements can detect systemic fat-free mass depletion in patients with chronic obstructive pulmonary disease

F.F. Sanchez, M.M. Faganello, S.E. Tanni, P.A. Lucheta, N.G. Pelegrino, S.H. Hasegawa, S.M. Ribeiro and I. Godoy

The Brazilian Journal of Medical and Biological Research is partially financed by

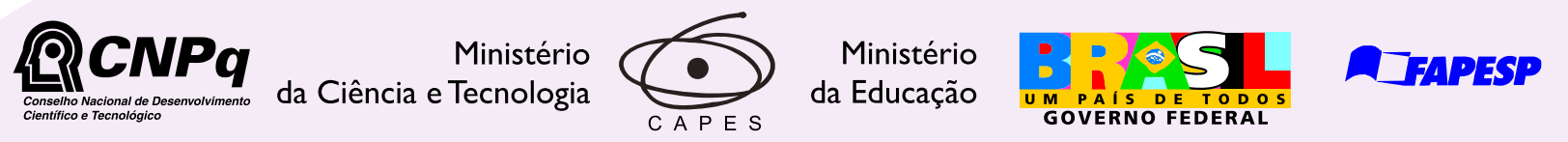

Institutional Sponsors

soripo
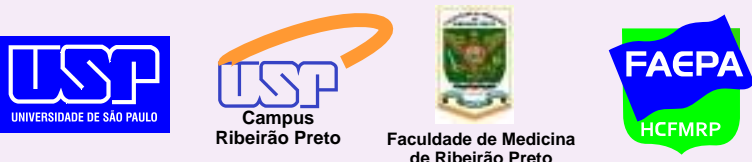

de Ribeirão Preto

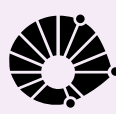

$\oplus$ SHIMADZU

GE Healthcare
Hotsite of proteomics metabolomics developped by:

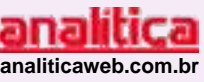

Thermo SCIENTIFIC 


\title{
Anthropometric midarm measurements can detect systemic fat-free mass depletion in patients with chronic obstructive pulmonary disease
}

\author{
F.F. Sanchez ${ }^{1}$, M.M. Faganello², S.E. Tanni ${ }^{3}$, P.A. Lucheta ${ }^{3}$, N.G. Pelegrino ${ }^{3}$, \\ S.H. Hasegawa ${ }^{3}$, S.M. Ribeiro 4 and I. Godoy ${ }^{3}$ \\ ${ }^{1}$ Departamento de Fisioterapia, Universidade Federal do Amazonas, Manaus, AM, Brasil \\ 2Departamento de Fisioterapia, Centro Universitário Católico Salesiano Auxilium, Unisalesiano, Lins, SP, Brasil \\ ${ }^{3}$ Departamento de Clínica Médica, ${ }^{4}$ Departamento de Doenças Tropicais e Diagnóstico por Imagem, \\ Faculdade de Medicina de Botucatu, Universidade Estadual Paulista, Botucatu, SP, Brasil
}

\begin{abstract}
Our objective was to determine whether anthropometric measurements of the midarm (MA) could identify subjects with whole body fat-free mass (FFM) depletion. Fifty-five patients (31\% females; age: $64.6 \pm 9.3$ years) with mild/very severe chronic obstructive pulmonary disease (COPD), 18 smokers without COPD (39\% females; age: $49.0 \pm 7.3$ years) and 23 never smoked controls (57\% females; age: $48.2 \pm 9.6$ years) were evaluated. Spirometry, muscle strength and MA circumference were measured. MA muscle area was estimated by anthropometry and MA cross-sectional area by computerized tomography (CT) scan. Bioelectrical impedance was used as the reference method for FFM. MA circumference and MA muscle area correlated with FFM and biceps and triceps strength. Receiver operating characteristic curve analysis showed that MA circumference and MA muscle area cut-off points presented sensitivity and specificity $>82 \%$ to discriminate FFM-depleted subjects. CT scan measurements did not provide improved sensitivity or specificity. For all groups, there was no significant statistical difference between MA muscle area [35.2 (29.3-45.0) $\mathrm{cm}^{2}$ ] and MA cross-sectional area values [36.4 (28.5-43.3) $\left.\mathrm{cm}^{2}\right]$ and the linear correlation coefficient between tests was $r=0.77(P<0.001)$. However, Bland-Altman plots revealed wide $95 \%$ limits of agreement $(-14.7$ to $15.0 \mathrm{~cm}^{2}$ ) between anthropometric and CT scan measurements. Anthropometric MA measurements may provide useful information for identifying subjects with whole body FFM depletion. This is a low-cost technique and can be used in a wider patient population to identify those likely to benefit from a complete body composition evaluation.
\end{abstract}

Key words: Fat-free mass depletion; Midarm anthropometry; Chronic obstructive pulmonary disease; Malnutrition; Nutritional status assessment

\section{Introduction}

Weight loss and muscle wasting are common systemic manifestations in patients with chronic obstructive pulmonary disease (COPD) (1). The prevalence of reduced body mass index (BMI) values or fat-free mass (FFM) depletion varies between 25 and $35 \%$ in clinically stable outpatients with COPD $(1,2)$. Recent studies have shown that decreased whole body FFM is associated with increased mortality risk in these patients, even in those with normal BMI $(3,4)$. Furthermore, decreased FFM contributes to peripheral and respiratory muscle weakness, reducing maximum exercise capacity and impairing health-related quality of life in patients with COPD (5-9). The high prevalence of FFM depletion and its association with an adverse outcome have increased the importance of identifying reliable cost-effective methods for assessing FFM in these patients.

Malnutrition is acknowledged to exist in COPD patients when $\mathrm{BMI}<21 \mathrm{~kg} / \mathrm{m}^{2}$ and is associated with the worst prognosis in these patients (10). However, BMI is an inaccurate estimate of the fat and non-fat constituents of body weight (10). In fact, recent studies have shown FFM depletion prevalence to be higher than the presence of lower BMI values in COPD patients (11-13). FFM has therefore been considered a more sensitive tool for detecting undernutrition in COPD patients (2). Although whole body and/or localized FFM measurements using bioelectrical impedance, computed tomography, and dual-energy X-ray absorptiometry provide clinically relevant information on nutritional status and prognosis in COPD patients, their use is limited by

Correspondence: F.F. Sanchez, Rua Pernambuco, 92, Casa 5, 69058-480 Manaus, AM, Brasil. E-mail: fersanchez1@hotmail.com

Received September 12, 2010. Accepted February 14, 2011. Available online March 4, 2011. Published May 16, 2011. 
the cost of equipment and associated technical difficulties $(3,14,15)$.

Anthropometric measurements are inexpensive and quick. They provide an indirect estimate of nutritional status and body composition when applied by a trained health professional. A prospective study followed 96 male COPD patients for tree years and showed that midarm (MA) muscle area values $\leq 25 \%$ of reference values were related to a 3.4-fold increase in mortality risk (15). In addition, a survey of 178 patients with COPD showed that $62.7 \%$ of them, with normal BMI, and including $20.7 \%$ overweight patients, showed muscle depletion by MA muscle area estimation (16). These data suggest that anthropometric MA measurements could be valuable as a screening tool to identify patients with whole body FFM depletion. However, there is no study reported in the literature that has evaluated the clinical utility of anthropometric measurements of the MA to identify whole body FFM depletion in COPD patients.

Therefore, the aim of the present study was to determine whether the anthropometric MA measurements, MA circumference and MA muscle area could be used to identify patients with COPD having whole body FFM depletion.

\section{Patients and Methods}

\section{Study population}

Fifty-five (31\% females) consecutive subjects evaluated at the University Hospital Pulmonary Outpatient Clinic (Botucatu Medical School, Botucatu, SP, Brazil) were invited to participate in this study. Major inclusion criteria were a clinical diagnosis of COPD according to Global Initiative for Chronic Obstructive Lung Disease (GOLD) (17) and Brazilian Thoracic Society criteria (18), age $\geq 40$ years, smoking history $\geq 10$ pack years, and a $<70 \%$ post-bronchodilator forced expiratory volume in $1 \mathrm{~s}\left(\mathrm{FEV}_{1}\right) /$ forced vital capacity (FVC) ratio. All patients were optimized in terms of standard medical therapy according to GOLD and Brazilian Thoracic Society guidelines $(17,18)$. Patients not considered to be clinically stable (i.e., who presented changes in medication dose or frequency, disease exacerbation, or hospital admissions in the preceding 8 weeks) were excluded. The following factors were also considered grounds for exclusion: chronic diseases such as malignant disorders, cardiovascular disease, insulin-dependent diabetes mellitus, oral corticosteroids, treatment noncompliance, and inability to perform the lung function test. Since smoking by itself has also been shown to interfere with muscle function $(19,20)$, 18 smokers without COPD (39\% females) aged $\geq 40$ years, with a smoking history $\geq 10$ pack years, and $\geq 70 \%$ postbronchodilator $\mathrm{FEV}_{1} / \mathrm{FVC}$ ratio were also included in the study. The control group consisted of 23 individuals $(57 \%$ females), aged $\geq 40$ years without a history of smoking or comorbidities and with normal serum biochemical tests (glucose, urea, creatinine, aspartate aminotransferase, and alanine aminotransferase) and spirometry values. The study was approved by the Research Ethics Committee of Faculdade de Medicina de Botucatu, UNESP, and all subjects gave informed written consent to participate.

\section{Measurements}

Spirometry and blood gases. Spirometry was performed before and $15 \mathrm{~min}$ after $400-\mu \mathrm{g}$ salbutamol inhalation using a KOKO spirometer (Ferraris KOKO, USA) according to American Thoracic Society criteria (21). $\mathrm{FEV}_{1}$ values are reported in liters, percentages of FVC, and as percentages of reference values (22). Pulse oximetry $\left(\mathrm{SpO}_{2} \%\right)$ was assessed using a portable Onyx oxymeter (Model 9500 Oxymeter; Nonin Medical Inc., USA).

Anthropometric measurements and body composition analysis. All anthropometric measurements were performed by the same trained dietitian. The following anthropometric parameters were recorded: body weight and height, MA circumference, and triceps skinfold thickness. MA circumference was measured to the nearest $0.1 \mathrm{~cm}$ using a non-stretch tape and triceps skinfold thickness was measured to the nearest $0.5 \mathrm{~mm}$ using a Lange skinfold caliper (Cambridge Scientific Industries, USA). BMI was calculated $\left(\mathrm{BMI}=\right.$ weight in $\mathrm{kg} /$ height in $\mathrm{m}^{2}$ ) and anthropometric MA muscle area was estimated using a standard equation (23). The corresponding percentiles were determined based on Frisancho's tables (23). Body composition was evaluated using a bioelectrical impedance analyzer (BIA 101A; RJL systems, USA) according to the guidelines of the European Society for Clinical Nutrition and Metabolism (24). FFM was estimated $(\mathrm{kg})$ using a group-specific regression equation developed by Kyle et al. $(25,26)$ and FFM index (FFMI) was calculated as FFM/height ${ }^{2}$. Fat mass was defined as total body weight minus FFM. Lean body mass depletion was defined as an FFMI $<15 \mathrm{~kg} / \mathrm{m}^{2}$ (women) and $<16 \mathrm{~kg} / \mathrm{m}^{2}$ (men) (3). Peripheral muscle mass was evaluated by computed tomography (CT); midthigh and MA cross-sectional areas were obtained as previously described (27). Briefly, CT midthigh cross-sectional area was measured halfway between the pubic symphysis and the femur inferior condyle. In the arm, CT MA cross-sectional area was measured between the head of the humerus and the olecranon (Scanner, Shimadzu SCT-7000 TS, Japan). Each image was $10-$ to $20-\mathrm{mm}$ thick and was taken at 120 $\mathrm{Kv}$, with a 1-s scanning time.

Peripheral muscle strength measurements. Peripheral muscle strength was assessed by determining the one-repetition maximum (1RM) in $\mathrm{kg}(28)$. The agreed convention for $1 \mathrm{RM}$ is the heaviest weight that can be lifted throughout the complete range of motions related to the exercise performed; this was assessed for each of three exercises performed on weight training equipment. Patients were required to perform the following exercises: leg press (quadriceps, gluteus, hamstrings, and calf muscles), triceps pulley (triceps), and biceps curl (biceps). A pre-test warmup of 10 repetitions with a light load was performed to 
minimize learning effects. The $1 \mathrm{RM}$ test was initiated at a weight near the suspected maximum to minimize repetition fatigue. All participants attained 1RM within four attempts. A 2- to 3-min rest was permitted between repetitions. The Valsalva maneuver was avoided, and the correct performance of the exercise technique for each muscle group was emphasized.

\section{Statistical analysis}

Results are reported as means and standard deviations/errors or median (interquartile range). All statistical analyses was conducted using Systat 12 (Inc., USA) and Medcalc 9.4 (Belgium) softwares. Differences between groups were evaluated by analysis of variance (ANOVA) or nonparametric analysis for data having skewed distribution, and Dunn and chi-square tests were subsequently used for categorical variables. Comparison between groups of MA circumference, anthropometric MA muscle area, MA cross-sectional area, and midthigh cross-sectional area were adjusted by gender and age using ANCOVA. Pearson product moment correlation (continuous, r) or Spearman rank correlation ( $r s$ ) was used to determine relationships between variables. Bland-Altman analysis was conducted to assess agreement between anthropometric and CT scan analysis of upper-limb FFM. This graphic method plots the difference in scores between two measurements against the mean for each subject and determines if the new method agrees sufficiently well with the old one. The presentation of the $95 \%$ limits of agreement is for visual judgment of how well the two methods of measurement agree. The interpretation can be evaluated taking into consideration that a smaller range between these two limits means a better agreement between the methods. With FFMI as a reference standard, a receiver operating characteristic (ROC) curve was generated for MA circumference, anthropometric MA muscle area, MA cross-sectional area, and midthigh crosssectional area to determine the cut-off points to be used to discriminate systemic FFM depletion. The cut-off risk point for each variable was defined from the highest sensitivity - (1-specificity) value in the ROC curve. The area under the ROC curve (AUC) indicated the probability of discriminating systemic FFM depletion. A contingency table was prepared to analyze the relationship between the localized FFM by anthropometry and CT scan and the FFMI. These tables were used to determine sensitivity, specificity, positive predictive value, and negative predictive value. Statistical tests comparing AUCs were conducted by the $t$-test. The level of significance was set at $P<0.05$.

\section{Results}

The characteristics of controls, smokers without COPD, and COPD patients are presented in Table 1. COPD patients were older, presented lower $F E V_{1}$ values ( $\%$ predicted) and $\mathrm{FEV}_{1} / \mathrm{FVC}$ ratios compared to smokers without COPD and controls. COPD patients had significantly lower FFM $(\mathrm{kg})$ values than controls, but BMI and FFMI $\left(\mathrm{kg} / \mathrm{m}^{2}\right)$ values were similar in all three groups.

Comparison between groups according to MA circumference, upper and lower limb localized FFM and peripheral muscle strength values is presented in Table 2. Anthropometric MA muscle area and CT scan measurement for upper limb muscle areas were similar between groups $(P=0.23$; $P=0.89$ ). MA circumference was lower in COPD patients and midthigh cross-sectional area was significantly lower in smokers without COPD and in COPD patients than in controls. MA circumference correlated with FFM (kg; $r=$ 0.60 ; $P<0.001)$, biceps strength $(r=0.46$; $P<0.001)$, and triceps strength $(r=0.57 ; P<0.001)$. MA muscle area correlated with FFM $(\mathrm{kg} ; \mathrm{r}=0.71 ; \mathrm{P}<0.001)$, biceps strength $(r=0.59 ; P<0.001)$, and triceps strength $(r=0.60 ; P<$ 0.001). MA cross-sectional area correlated with FFM (kg; $r=0.80 ; P<0.001)$, biceps strength $(r=0.70 ; P<0.001)$, and triceps strength $(r=0.72 ; P<0.001)$. Midthigh crosssectional area correlated with FFM $(\mathrm{kg} ; \mathrm{r}=0.85 ; \mathrm{P}<0.001)$ and leg press strength $(r=0.52 ; P<0.001)$.

Table 1. Demographic characteristics, spirometry, and body composition of participants in this study.

\begin{tabular}{lccc}
\hline & Controls $(\mathrm{N}=23)$ & Smokers without COPD $(\mathrm{N}=18)$ & COPD $(\mathrm{N}=55)$ \\
\hline Age (years) & $48.2 \pm 6.9$ & $49.0 \pm 7.3$ & $64.6 \pm 9.3^{* \star}$ (ANOVA) \\
Sex (male/female) & $10 / 13$ & $11 / 7$ & $38 / 17$ (chi-square test) \\
FEV $1 \%$ predicted) & $112.0 \pm 14.7$ & $105.0 \pm 18.0$ & $54.5 \pm 22.7^{* *}$ (ANOVA) \\
FEV $1 /$ FVC $(\%)$ & $83.0(81.2 ; 88.0)$ & $78.5(74.0 ; 80.0)$ & $49.0(38.0 ; 61.7)^{\star *}$ (Kruskal-Wallis test) \\
BMl $\left(\mathrm{kg} / \mathrm{m}^{2}\right)$ & $26.3 \pm 3.5$ & $24.3 \pm 3.8$ & $25.4 \pm 5.1$ (ANOVA) \\
FFM $(\mathrm{kg})$ & $46.7 \pm 7.5$ & $45.1 \pm 8.1$ & $41.5 \pm 7.2^{*}($ ANOVA) \\
FFMI $\left(\mathrm{kg} / \mathrm{m}^{2}\right)$ & $17.2 \pm 2.0$ & $16.8 \pm 2.0$ & $15.9 \pm 2.2$ (ANOVA) \\
\hline
\end{tabular}

Data are reported as means $\pm \mathrm{SD}$ or median (interquartile range). COPD = chronic obstructive pulmonary disease; $\mathrm{FEV}_{1}=$ forced expiratory volume in $1 \mathrm{~s} ; \mathrm{FVC}=$ forced vital capacity; BMI = body mass index; FFM = fat-free mass; $\mathrm{FFMI}=$ fat-free mass index. ${ }^{*} \mathrm{P}<0.05$ compared to controls; ${ }^{* *} \mathrm{P}<0.05$ compared to smokers without COPD. 
Since two-way ANOVA did not indicate differences in anthropometric MA muscle area or MA cross-sectional area between groups, data from all subjects were pooled together for additional analyses. There was no significant difference between MA muscle area values determined anthropometrically [35.2 (29.3-45.0) $\mathrm{cm}^{2}$ ] and by CT scan [36.4 (28.5-43.3) $\left.\mathrm{cm}^{2}\right]$ and the linear correlation coefficient between tests was $r=0.77(P<0.001)$. However, BlandAltman plots (Figure 1) revealed wide $95 \%$ limits of agreement $\left(-14.7\right.$ to $\left.15.0 \mathrm{~cm}^{2}\right)$ between anthropometric and CT scan measurements. Values of AUC, sensitivity, specificity, positive and negative predictive values for cut-off points of MA circumference, anthropometric MA muscle areas, MA

Table 2. Muscle mass and peripheral muscle strength measurements of controls, smokers without COPD, and COPD patients.

\begin{tabular}{lrcc}
\hline & $\begin{array}{c}\text { Controls } \\
(\mathrm{N}=23)\end{array}$ & $\begin{array}{c}\text { Smokers without } \\
\text { COPD }(\mathrm{N}=18)\end{array}$ & COPD $(\mathrm{N}=55)$ \\
\hline MAC $(\mathrm{cm})$ & $29.6 \pm 3.2$ & $27.7 \pm 3.2$ & $27.0 \pm 4.3^{*}$ \\
MAMA $\left(\mathrm{cm}^{2}\right)$ & $38.3 \pm 2.4$ & $33.1 \pm 2.6$ & $37.0 \pm 1.6$ \\
MACSA $\left(\mathrm{cm}^{2}\right)$ & $37.8 \pm 1.8$ & $34.6 \pm 2.0$ & $36.4 \pm 1.2$ \\
Biceps $(\mathrm{kg})$ & $24.6 \pm 1.4$ & $22.5 \pm 1.8$ & $20.2 \pm 0.9$ \\
Triceps $(\mathrm{kg})$ & $20.1 \pm 1.2$ & $17.6 \pm 1.6$ & $19.0 \pm 0.8$ \\
MTCSA $\left(\mathrm{cm}^{2}\right)$ & $138.8 \pm 4.8$ & $120.0 \pm 5.2^{*}$ & $124.6 \pm 3.2^{*}$ \\
Leg press $(\mathrm{kg})$ & $82.9 \pm 5.8$ & $79.6 \pm 7.3$ & $83.3 \pm 3.7$ \\
\hline
\end{tabular}

Data are reported as means \pm SEM. COPD = chronic obstructive pulmonary disease; MAC = midarm circumference; MAMA = anthropometric midarm muscle area; MACSA = midarm muscle cross-sectional area determined by computed tomography; MTCSA = midthigh muscle cross-sectional area determined by computed tomography. ${ }^{*} \mathrm{P}<0.05$ compared to controls (ANCOVA adjusted for gender and age). cross-sectional area, and midthigh cross-sectional area, according to gender, are presented in Table 3. As shown in Table 3 and Figure 2, anthropometric values of MA muscle area $<32.5 \mathrm{~cm}^{2}$ (males), and $<31.7 \mathrm{~cm}^{2}$ (females), had the highest sensitivity and specificity and AUC $(0.87 ; P<0.001)$ to discriminate between FFM-depleted and non-depleted subjects. In addition, data for MA circumference indicated that values $<26.0 \mathrm{~cm}$ (males) and $<27.5 \mathrm{~cm}$ (females)

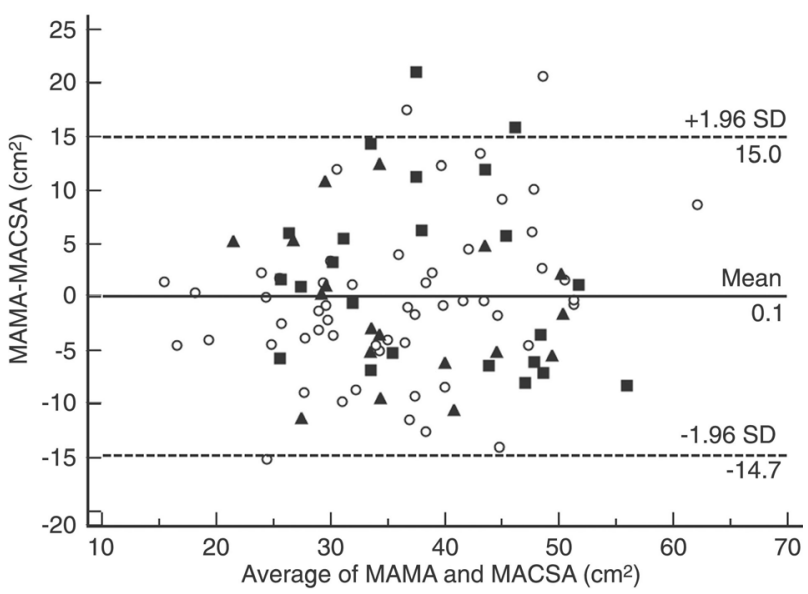

Figure 1. Limits of agreement (Bland-Altman plot) between anthropometric midarm muscle area (MAMA) and computed tomography midarm cross-sectional area (MACSA) in chronic obstructive pulmonary disease patients (COPD) (open circles), smokers without COPD (filled triangles), and controls (filled squares). This graphic method plots the difference of the scores of two measurements against the mean for each subject and indicates if the MAMA method agrees sufficiently well with the MACSA. BlandAltman plots revealed wide $95 \%$ limits of agreement $(-14.7$ to $15.0 \mathrm{~cm}^{2}$ ) between anthropometric and CT scan measurements.

Table 3. Diagnostic performance of the cut-off points for MAC, anthropometric MAMA, MACSA, and MTCSA for discriminating subjects with whole body FFM depletion.

\begin{tabular}{|c|c|c|c|c|c|c|c|c|}
\hline & \multicolumn{2}{|c|}{ MAC } & \multicolumn{2}{|c|}{ MAMA } & \multicolumn{2}{|c|}{ MACSA } & \multicolumn{2}{|c|}{ MTCSA } \\
\hline & $\begin{array}{c}\text { Male } \\
(N=59)\end{array}$ & $\begin{array}{l}\text { Female } \\
(\mathrm{N}=37)\end{array}$ & $\begin{array}{c}\text { Male } \\
(\mathrm{N}=59)\end{array}$ & $\begin{array}{l}\text { Female } \\
(\mathrm{N}=37)\end{array}$ & $\begin{array}{c}\text { Male } \\
(N=59)\end{array}$ & $\begin{array}{l}\text { Female } \\
(\mathrm{N}=37)\end{array}$ & $\begin{array}{c}\text { Male } \\
(\mathrm{N}=59)\end{array}$ & $\begin{array}{l}\text { Female } \\
(\mathrm{N}=37)\end{array}$ \\
\hline Cut-off point (cm) & 26.0 & 27.5 & 32.5 & 31.7 & 36.9 & 29.9 & 132.0 & 106.1 \\
\hline Sensitivity (\%) & 84.6 & 88.9 & 81.2 & 82.4 & 77.8 & 94.0 & 77.8 & 82.0 \\
\hline Specificity (\%) & 82.4 & 82.4 & 86.4 & 84.2 & 88.9 & 70.0 & 75.1 & 70.0 \\
\hline AUC & 0.86 & 0.88 & 0.87 & 0.87 & 0.85 & 0.85 & 0.81 & 0.81 \\
\hline Positive predictive value (\%) & 40.5 & 48.4 & 73.7 & 81.2 & 72.2 & 66.7 & 56.0 & 68.4 \\
\hline Negative predictive value (\%) & 89.4 & 100 & 90.0 & 84.0 & 89.4 & 85.7 & 90.3 & 81.2 \\
\hline
\end{tabular}

Cut-off points were determined by receiver operating characteristic curve analysis according to gender in all subjects included in the study. FFM depletion was defined as an FFM index $<15 \mathrm{~kg} / \mathrm{m}^{2}$ (women) and $<16 \mathrm{~kg} / \mathrm{m}^{2}$ (men) (3). FFM = fat-free mass; $M A C=$ midarm circumference; $M A M A=$ anthropometric midarm muscle area; MACSA = midarm muscle cross-sectional area determined by computed tomography; MTCSA = midthigh muscle cross-sectional area determined by computed tomography; AUC = area under the curve. 
presented sensitivity and specificity $>82 \%$ and AUC $>85 \%$ to discriminate between FFM-depleted and non-depleted subjects. No difference in cut-off points was identified between COPD patients, smokers without COPD, and controls (data not shown). When anthropometric MA muscle area values $\leq 25 \%$ of reference values (15) were considered to determine FFM depletion, the cut-off points showed lower sensitivity $($ male $=100.0 \%$; female $=75.0 \%$ ), specificity ( male $=48.8 \%$; female $=90.9 \%$ ), positive predictive value (male $=12.0 \%$; female $=78.8 \%)$, and negative predictive value $($ male $=100 \%$; female $=87 \%$ ) than those determined in the present study.

\section{Discussion}

The results of this study showed that midarm anthropometric measurements (MA circumference and MA muscle area) correlated significantly with measurements of systemic FFM and muscle strength, and presented a greater than $82 \%$ sensitivity and specificity in identifying individuals with whole body FFM depletion according to FFMI. However, the agreement between anthropometric and CT scan measurements is poor and measurements are not interchangeable; therefore, CT scans did not provide improved sensitivity or specificity in identifying individuals with whole body FFM depletion.

The ability of MA circumference and anthropometric MA muscle area cut-off points to discriminate between individuals with and without whole body FFM depletion, according to FFMI, was also greater than the 25th percentile of reference values (23), especially in men. In this context, midarm anthropometric measurements seem to be sensitive markers of FFM depletion and may be useful in clinical settings where more advanced and expensive techniques for whole body FFM determination are not available.

In the current study, systemic FFM was estimated using bioelectrical impedance measurements, an accurate technique that has been validated and evaluated to assess body composition in patients with COPD (29). Although bioelectrical impedance does not represent a gold standard reference method for measurement of whole body FFM, the estimate of FFM using bioelectrical impedance was used in the National Health and Nutrition Examination Survey III (NHANES III) analysis to identify skeletal muscle cut-off points associated with a high likelihood of physical disability in older subjects and in studies showing the influence of FFM on morbidity and mortality in COPD patients $(3,4,30)$.

The cut-off points for anthropometric MA measurements determined in this study provided good sensitivity and specificity to identify systemic FFM depletion in control subjects, smokers without COPD, and COPD patients. To our knowledge this is the first study to evaluate the clinical utility of these measurements to identify whole body FFM depletion in COPD patients.

However, anthropometric MA muscle area has been

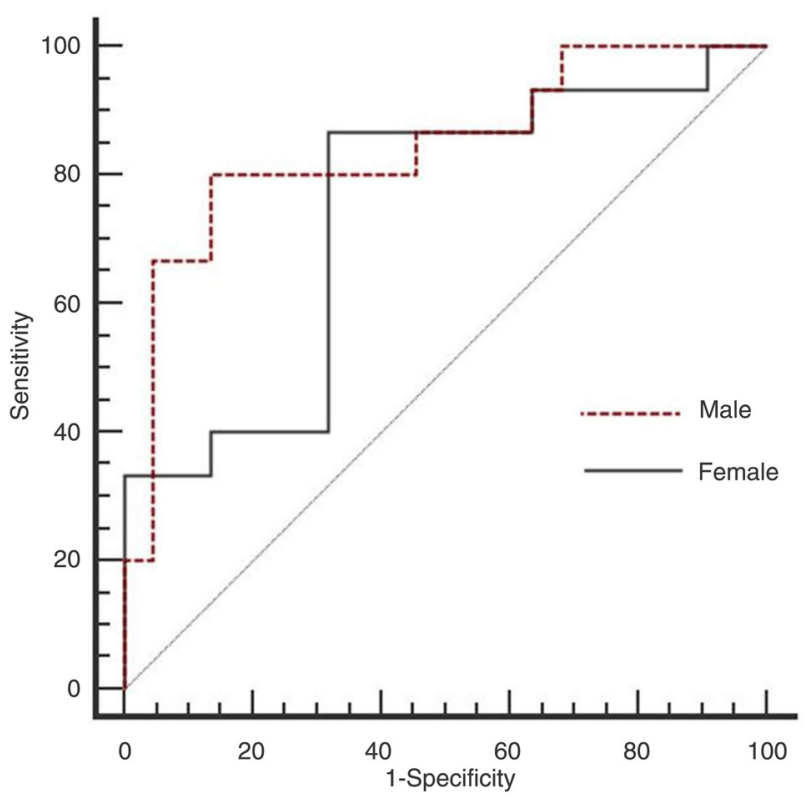

Figure 2. Receiver operating characteristic curve analysis of anthropometric midarm muscle area (MAMA) to discriminate subjects with whole body fat-free mass depletion (FFM) according to gender. FFM depletion was defined as FFM index $<15 \mathrm{~kg} / \mathrm{m}^{2}$ for women and $<16 \mathrm{~kg} / \mathrm{m}^{2}$ for men (3). Sensitivity is the true-positive rate and 1 -specificity the false-positive rate. The area under the curve (AUC; 95\% confidence interval) was $0.87(0.75 ; 0.94)$ for males, and $0.87(0.72 ; 0.96)$ for females, $\mathrm{P}<0.001$.

proposed as an appropriate measurement for indirect evaluation of nutritional status and reference population values $<25$ th percentile of reference values have been considered to be an indicator of muscle mass depletion (31) and were related to the prognosis of patients with COPD (15). The present study showed that the anthropometric MA muscle area cut-off point for men $\left(32.5 \mathrm{~cm}^{2}\right)$ was lower than the 25 th percentile of reference values for the reference population (40.2 to $48.7 \mathrm{~cm}^{2}$ ) (23). For women, the cut-off point for anthropometric MA muscle area $\left(31.7 \mathrm{~cm}^{2}\right)$ was higher than the 25th percentile of reference values $\left(27.5\right.$ to $\left.28.8 \mathrm{~cm}^{2}\right)$ (23). An explanation for these discrepancies may be that anthropometric reference values for the healthy Brazilian population have not been established and the predictive values used here were the international anthropometrics standards described by Frisancho (23).

The relationship between arm muscle circumference and systemic body cell mass depletion has also been reported for patients listed for liver transplantation (32). In a study evaluating multiple standard nutritional parameters, MA muscle circumference and MAcircumference were positively correlated with body cell mass measured by the isotope dilution technique and multivariable analysis showed that MA circumference and handgrip strength were the best predictors for body cell mass (32). MA circumference has 
also been shown to be a significant predictor of mortality in previous studies $(33,34)$.

In agreement with previous findings, we demonstrated large discrepancies between relative MA cross-sectional area when assessed by anthropometry and CT scan (3537 ). When anthropometric MA muscle area and MA crosssectional area values for controls, smokers without COPD, and COPD patients of both genders were pooled together and compared, no significant difference was found and both measurements presented a highly significant correlation with whole body FFM and muscle strength. However, BlandAltman analyses showed large discrepancies between the two methods for estimating relative MAcross-sectional area. Previous studies have also shown discrepancies between these two methods, with anthropometry overestimating arm muscle area by $10-40 \%$, mainly in individuals with large fat areas (35-37). A study in Brazil showed that, despite a good correlation between CT and anthropometric estimates, fat area was $29 \%$ higher and muscle area $4-5 \%$ lower when estimated by CT measurements and anthropometric measurements, respectively (38). In the present study, the relationship between whole body FFM, assessed by bioelectrical impedance, and CT estimate for MA area $(r=$ $0.80 ; P<0.001$ ) was similar to values previously obtained in obese, healthy, and malnourished patients of both genders $(r=0.88$; $P<0.001)$ (38).

FFM depletion of the legs has been shown to be a strong predictor of morbidity and mortality in COPD patients (14) and the present study found a strong relationship between lower limb muscle area determined by CT scan and whole body FFM ( $r=0.85$; $P<0.001)$, as previously reported by Ohkawa et al. (39) $(r=0.85$; $P<0.001)$ for hemodialysis patients. However, in the present study, analysis of the results showed that the midthigh cross-sectional area presented lower sensitivity, specificity, and positive predictive value compared to anthropometric MA muscle area and MA cross-sectional area in discriminating subjects with

\section{References}

1. Global initiative for chronic obstructive lung disease. Update global strategy for the diagnosis, management, and prevention of chronic obstructive pulmonary disease. Update 2009; 1-109. http://www.goldcopd.org.

2. Anker SD, John M, Pedersen PU, Raguso C, Cicoira M, Dardai E, et al. ESPEN Guidelines on Enteral Nutrition: Cardiology and Pulmonology. Clin Nutr 2006; 25: 311-318.

3. Schols AM, Broekhuizen R, Weling-Scheepers CA, Wouters EF. Body composition and mortality in chronic obstructive pulmonary disease. Am J Clin Nutr 2005; 82: 53-59.

4. Vestbo J, Prescott E, Almdal T, Dahl M, Nordestgaard BG, Andersen $\mathrm{T}$, et al. Body mass, fat-free body mass, and prognosis in patients with chronic obstructive pulmonary disease from a random population sample: findings from the Copenhagen City Heart Study. Am J Respir Crit Care Med whole body FFM depletion. Loss of FFM is a natural aging process, a condition referred to as sarcopenia, which progresses at a faster rate in lower-body FFM than in upper-body FFM (40). This may be an explanation for a better performance of anthropometric MA muscle area and MA cross-sectional area in predicting whole body FFM in the present population.

The present study has some limitations. First, validity and reliability were not tested; however, the same trained dietitian performed all the measurements and determining MA circumference and skinfold thickness are very well-established techniques. Second, the cross-sectional analysis does not permit an evaluation of the prognostic value of these measurements.

The findings of the present study suggest that, for control subjects, smokers without COPD, and COPD patients of both genders, MA anthropometric measurements provide useful information to identify those with whole body FFM depletion. MA circumference and muscle area have similar discriminative properties and also show no advantage of using CT scan assessments. Anthropometric MA circumference and muscle area can be rapidly obtained and are lowcost techniques performed without the need for advanced equipment. Therefore, they can be used in a wider patient population to identify those likely to benefit from a complete body composition evaluation. Because the findings were derived from a specific population, it is not known whether they would be relevant for other ethnic groups. Future studies are required to evaluate specific cut-off points for each population and to develop and cross-validate prediction models for identifying whole-body FFM depletion using MA anthropometric measurements.

\section{Acknowledgments}

Research supported by FAPESP (\#04/00517-4). F.F. Sanchez is the recipient of a Scholarship grant from CAPES.
2006; 173: 79-83.

5. Schols AM, Mostert R, Soeters PB, Wouters EF. Body composition and exercise performance in patients with chronic obstructive pulmonary disease. Thorax 1991; 46: 695-699.

6. Engelen MP, Schols AM, Baken WC, Wesseling GJ, Wouters EF. Nutritional depletion in relation to respiratory and peripheral skeletal muscle function in out-patients with COPD. Eur Respir J 1994; 7: 1793-1797.

7. Baarends EM, Schols AM, Mostert R, Wouters EF. Peak exercise response in relation to tissue depletion in patients with chronic obstructive pulmonary disease. Eur Respir $J$ 1997; 10: 2807-2813.

8. Palange P, Forte S, Onorati P, Paravati V, Manfredi F, Serra $P$, et al. Effect of reduced body weight on muscle aerobic capacity in patients with COPD. Chest 1998; 114: 12-18. 
9. Mostert R, Goris A, Weling-Scheepers C, Wouters EF, Schols AM. Tissue depletion and health related quality of life in patients with chronic obstructive pulmonary disease. Respir Med 2000; 94: 859-867.

10. Wagner PD. Possible mechanisms underlying the development of cachexia in COPD. Eur Respir J 2008; 31: 492501.

11. Cano NJ, Roth H, Court-Ortune, Cynober L, Gerard-Boncompain M, Cuvelier A, et al. Nutritional depletion in patients on long-term oxygen therapy and/or home mechanical ventilation. Eur Respir J 2002; 20: 30-37.

12. Vermeeren MA, Creutzberg EC, Schols AM, Postma DS, Pieters WR, Roldaan AC, et al. Prevalence of nutritional depletion in a large out-patient population of patients with COPD. Respir Med 2006; 100: 1349-1355.

13. Steuten LM, Creutzberg EC, Vrijhoef HJ, Wouters EF. COPD as a multicomponent disease: inventory of dyspnoea, underweight, obesity and fat free mass depletion in primary care. Prim Care Respir J 2006; 15: 84-91.

14. Marquis K, Debigare R, Lacasse $Y$, LeBlanc $P$, Jobin J, Carrier $\mathrm{G}$, et al. Midthigh muscle cross-sectional area is a better predictor of mortality than body mass index in patients with chronic obstructive pulmonary disease. Am J Respir Crit Care Med 2002; 166: 809-813.

15. Soler-Cataluna JJ, Sanchez-Sanchez L, Martinez-Garcia MA, Sanchez PR, Salcedo E, Navarro M. Mid-arm muscle area is a better predictor of mortality than body mass index in COPD. Chest 2005; 128: 2108-2115.

16. Soler JJ, Sanchez L, Roman P, Martinez MA, Perpina M. [Prevalence of malnutrition in outpatients with stable chronic obstructive pulmonary disease]. Arch Bronconeumol 2004; 40: $250-258$

17. Fabbri LM, Hurd SS. Global strategy for the diagnosis, management and prevention of COPD: 2003 update. Eur Respir J 2003; 22: 1-2.

18. Jardim J, Oliveira J, Nascimento O. II Consenso Brasileiro de DPOC. J Bras Pneumol 2004; 30: S1-S42.

19. Montes de Oca M, Loeb E, Torres SH, De Sanctis J, Hernandez N, Talamo C. Peripheral muscle alterations in nonCOPD smokers. Chest 2008; 133: 13-18.

20. Wust RC, Morse Cl, de Haan A, Rittweger J, Jones DA, Degens $\mathrm{H}$. Skeletal muscle properties and fatigue resistance in relation to smoking history. Eur J Appl Physiol 2008; 104: 103-110.

21. Standardization of spirometry - 1987 update. Statement of the American Thoracic Society. Am Rev Respir Dis 1987; 136: 1285-1298.

22. Knudson RJ, Lebowitz MD, Holberg CJ, Burrows B. Changes in the normal maximal expiratory flow-volume curve with growth and aging. Am Rev Respir Dis 1983; 127: 725-734.

23. Frisancho AR. Anthropometrics standards for the assessment of growth and nutritional status. Ann Arbor: The University of Michigan Press; 1990.

24. Kyle UG, Bosaeus I, De Lorenzo AD, Deurenberg P, Elia M, Manuel GJ, et al. Bioelectrical impedance analysis - part II: utilization in clinical practice. Clin Nutr 2004; 23: 14301453.

25. Kyle UG, Pichard C, Rochat T, Slosman DO, Fitting JW, Thiebaud D. New bioelectrical impedance formula for patients with respiratory insufficiency: comparison to dualenergy X-ray absorptiometry. Eur Respir J 1998; 12: 960966.
26. Kyle UG, Genton L, Karsegard L, Slosman DO, Pichard C. Single prediction equation for bioelectrical impedance analysis in adults aged 20-94 years. Nutrition 2001; 17 : 248-253.

27. Bernard S, LeBlanc P, Whittom F, Carrier G, Jobin J, Belleau $\mathrm{R}$, et al. Peripheral muscle weakness in patients with chronic obstructive pulmonary disease. Am J Respir Crit Care Med 1998; 158: 629-634.

28. Powers SK, Howley ET. Testes de esforço para a avaliação do desempenho. In: Powers SK, Howley ET (Editors), Fisiologia do exercício: teoria e aplicação ao condicionamento e ao desempenho. São Paulo: Manole; 2000. p 371-390.

29. Lerario MC, Sachs $A$, Lazaretti-Castro M, Saraiva LG, Jardim JR. Body composition in patients with chronic obstructive pulmonary disease: which method to use in clinical practice? Br J Nutr 2006; 96: 86-92.

30. Janssen I, Baumgartner RN, Ross R, Rosenberg IH, Roubenoff $R$. Skeletal muscle cutpoints associated with elevated physical disability risk in older men and women. Am J Epidemiol 2004; 159: 413-421.

31. World Health Organization. World Health Organization Physical status: The use and interpretation of anthropometry. Report of a WHO expert committee. Geneva: WHO; 1995.

32. Figueiredo FA, Dickson ER, Pasha TM, Porayko MK, Therneau TM, Malinchoc M, et al. Utility of standard nutritional parameters in detecting body cell mass depletion in patients with end-stage liver disease. Liver Transp/ 2000; 6: $575-581$.

33. Powell-Tuck J, Hennessy EM. A comparison of mid upper arm circumference, body mass index and weight loss as indices of undernutrition in acutely hospitalized patients. Clin Nutr 2003; 22: 307-312.

34. Zhu S, Heo M, Plankey M, Faith MS, Allison DB. Associations of body mass index and anthropometric indicators of fat mass and fat free mass with all-cause mortality among women in the first and second National Health and Nutrition Examination Surveys follow-up studies. Ann Epidemiol 2003; 13: 286-293.

35. Heymsfield SB, Fulenwider T, Nordlinger B, Barlow R, Sones $\mathrm{P}$, Kutner M. Accurate measurement of liver, kidney, and spleen volume and mass by computerized axial tomography. Ann Intern Med 1979; 90: 185-187.

36. Heymsfield SB, McManus C, Smith J, Stevens V, Nixon DW. Anthropometric measurement of muscle mass: revised equations for calculating bone-free arm muscle area. $A m \mathrm{~J}$ Clin Nutr 1982; 36: 680-690.

37. Forbes GB, Brown MR, Griffiths HJ. Arm muscle plus bone area: anthropometry and CAT scan compared. Am J Clin Nutr 1988; 47: 929-931.

38. Jordao AA, Bellucci AD, Dutra de Oliveira JE, Sergio MJ. Midarm computerized tomography fat, muscle and total areas correlation with nutritional assessment data. Int $J$ Obes Relat Metab Disord 2004; 28: 1451-1455.

39. Ohkawa S, Odamaki M, Yoneyama T, Hibi I, Miyaji K, Kumagai $\mathrm{H}$. Standardized thigh muscle area measured by computed axial tomography as an alternate muscle mass index for nutritional assessment of hemodialysis patients. Am J Clin Nutr 2000; 71: 485-490.

40. Janssen I, Heymsfield SB, Baumgartner RN, Ross R. Estimation of skeletal muscle mass by bioelectrical impedance analysis. J Appl Physiol 2000; 89: 465-471. 